\title{
Gambaran pemanfaatan buku kesehatan ibu dan anak (KIA) oleh ibu hamil trimester iii tentang persiapan persalinan di Puskesmas Tempel 1
}

\author{
Esitra Herfanda ${ }^{1}$, Sri Subiyatun ${ }^{2}$ \\ ${ }^{1}$ Program Studi, D3 Kebidanan, Universitas Aisyiyah Yogyakarta, Indonesia \\ ${ }^{2}$ Program Studi, D3 Kebidanan, Universitas Aisyiyah Yogyakarta, Indonesia
}

\begin{abstract}
The quality of maternal and child health services $(\mathrm{MCH})$ is one of the factors that influence the occurrence of maternal and infant mortality. The results of the 2013 National Health Research Riskesdas KIA books are currently not optimally utilized, mothers who have MCH books (80.8\%) but who can show health power (40.4\%), who do not have MCH books (19.2\% ). Puskesmas Tempel 1 is a Puskesmas with an average visit of 200-250 people / day. The results of the preliminary study showed that the average number of visits of pregnant women was 100 people / month, after interviews with 5 pregnant women who did ANC, all pregnant women brought $\mathrm{MCH}$ books and read in passing. Mothers who know the contents and make use of the MCH book 1 person and 4 pregnant women lack knowledge of the contents and use the MCH book. The purpose of this activity is to know the description of the use of the $\mathrm{MCH}$ handbook by pregnant women in Puskesmas Tempel 1. The design of this study is quantitative descriptive. The sampling technique was purposive sampling, a sample size of 60 respondents. This study uses a questionnaire as a measurement tool and data analysis uses univariate. The result is an overview of the use of $\mathrm{MCH}$ books by pregnant women in Puskesmas Tempel 1 from the use of 60 respondents (100\%), the utilization of health information for 60 respondents (100\%). Conclusion: Utilization of the $\mathrm{MCH}$ handbook by pregnant women in Puskesmas Tempel 1 from the use and utilization of health information regarding maternity preparation $100 \%$ positive.
\end{abstract}

Keywords: Utilization, MCH Handbook, Pregnant Women

Kualitas pelayanan kesehatan ibu dan anak (KIA) merupakan salah satu faktor yg mempengaruhi terjadinya kematian ibu dan bayi. Hasil penelitian Riskesdas tahun 2013 secara nasional buku KIA saat ini belum dimanfaatkan secara optimal, ibu yang memiliki buku KIA $(80,8 \%)$ namun yang bisa menunjukan ketenaga kesehatan (40,4\%), yang tidak memiliki buku KIA (19,2\%). Puskesmas Tempel 1 merupakan Puskesmas dengan rata-rata kunjungan 200-250 orang/har. Hasil studi pendahuluan didapatkan jumlah rata-rata kunjungan ibu hamil sebanyak 100 orang/bulan, setelah dilakukan wawancara kepada 5 ibu hamil yang melakukan ANC, semua ibu hamil membawa buku KIA dan membaca secara sepintas. Ibu yang mengetahu isi dan memanfaatkan buku KIA 1 orang dan 4 orang ibu hamil kurang mengetahui isi dan memanfaatkan buku KIA. Tujuan dari kegiatan ini mengetahui gambaran pemanfaatan buku KIA oleh ibu hamil di Puskesmas Tempel 1. Desain penelitian ini adalah deskriftif kuantitatif. Teknik sampling adalah purposif sampling, besar sampel 60 responden. Penelitian ini menggunakan kuesioner sebagai alat ukur dan analisa data menggunakan univariat. Hasilnya Gambaran pemanfaatan buku KIA oleh ibu hamil di Puskesmas Tempel 1 dari penggunaan sebanyak 60 responden (100\%), pemanfaatan informasi kesehatan sebanyak 60 responden (100\%). Kesimpulan:Pemanfaatan buku KIA oleh ibu hamil di puskesmas Tempel 1 dari penggunaan dan pemanfaatan informasi kesehatan mengenai persiapan persalinan $100 \%$ positif 
Kata Kunci: Pemanfaatan, Buku KIA, Ibu hamil

"Korespondensi Penulis : Esitra Herfanda (email (esitra_herfanda@unisayogya.ac.id)

\section{Pendahuluan}

Angka kematian ibu (AKI) dan angka kematian Bayi (AKB) merupakan indikator atau tolok ukur dalam bidang kesehatan. Kualitas pelayanan Kesehatan Ibu dan Anak (KIA) adalah salah satu faktor yang sangat memengaruhi terjadinya kematian ibu maupun bayi. Bagian yang tidak terpisahkan dalam pelayanan KIA adalah pemanfaatan buku KIA. Buku KIA saat ini belum dimanfaatkan secara optimal. Keberhasilan penggunaan buku KIA hanya terjadi apabila ibu, suami, keluarga aktif membaca, mempelajari, memahami secara bertahap isi buku KIA, dan menerapkan dalam kehidupan sehari-hari. Hasil penelitian Riskesdas tahun 2013 secara nasional, ibu yang memiliki buku KIA $(80,8 \%)$ namun yang bisa menunjukan ketenaga kesehatan $(40,4 \%)$ sedangkan ibu yang tidak memiliki buku KIA (19,2\%) (Kemenkes 2015).

Program Kesehatan Ibu dan Anak (KIA) adalah merupakan salah satu prioritas utama pembangunan kesehatan di Indonesia. Program ini bertanggung jawab terhadap pelayanan kesehatan bagi ibu hamil, ibu melahirkan, bayi dan neonatal. Salah satu tujuan ini adalah menurunkan kematian dan kejadian sakit pada ibu dan anak melalui peningkatan mutu pelayanan dan menjaga kesinambungan pelayanan kesehatan ibu dan perinatal di tingkat pelayanan dasar dan pelayanan rujukan primer (Sistiarani C, 2012).

Salah satu upaya pemerintah dalam meningkatkan mutu pelayanan kesehatan ibu dan anak adalah melalui penggunaan buku KIA. Penggunaan Buku KIA merupakan salah satu strategi pemberdayaan masyarakat terutama keluarga untuk memelihara dan mendapatkan pelayanan KIA yang berkualitas. Buku KIA merupakan alat komunikasi dan media informasi yang digunakan oleh tenaga kesehatan, keluarga dan Ibu hamil sendiri. Buku KIA berisi informasi dan materi tentang kesehatan ibu pada masa hamil, bersalin nifas dan KB serta materi kesehatan anak tentang perawatan bayi baru lahir sampai balita, perawatan balita seharihari,perawatan anak sakit, cara memberi makan anak dan membuat MP ASI, Dalam buku KIA sebenarnya sudah mencakup seluruhnya kebutuhan dari ibu hamil, bersalin, nifas hingga bayi dan balita. Dalam hal ini persiapan 
persalinan merupakan faktor yang penting di dalam ibu hamil menyiapkan segala sesuatunya untuk kelahiran bayinya. Kehamilan adalah masa berkembangnya hasil konsepsi dari awal konsepsi sampai proses awal persalinan (Manuaba,1998). Kehamilan merupakan salah satu ekspresi perwujudan diri, perwujudan identitas sebagai calon ibu dan ayah. Kebanggaan tersendiri bagi wanita dan mewujudkan feminisme, serta untuk menunjukkan jati diri seorang wanita (Admin,2009). Seorang wanita hamil tidak hanya mengalami proses - proses somatik, tetapi juga mengalami implikasi - implikasi psikologik yang mendalam dan membekas. Pengetahuan ibu hamil terhadap tanda-tanda persalinan sangatlah penting, karena dengan mengetahui tanda-tanda persalinan dapat diketahui bahwa persalinannya sudah dekat dan siap dalam persalinan sehingga ibu dan keluarga pun dapat lebih cepat ke rumah sakit atau ke klinik bersalin (Suririnah, 2004) diperkirakan sebanyak $90 \%$ kematian ibu terjadi pada saat sekitar persalinan, dan 95\% penyebab kematian adalah komplikasi obstetri yang sering tidak diperkirakan sebelumnya seperti perdarahan, infeksi, eklamsia, persalinan lama dan abortus komplikasi abortus. Kebijaksanaan departemen kesehatan untuk mempercepat penurunan Angka Kematian Ibu (AKI) adalah mengupayakan agar setiap persalinan ditolong atau minimal didampingi oleh bidan supaya mengurangi dua pertiga dari angka tingkat kematian bayi.

Berdasarkan profil Dinas Kesehatan Sleman tahun 2015, dari 25 Puskesmas yang ada Puskesmas Tempel 1 baru berubah menjadi puskesmas yang rawat inap dengan jumlah kunjungan ibu hamil rata-rata 50 orang/hari. Penelitian lain yang sudah dilakukan oleh Subiyatun menyatakan bahwa pemanfaatan buku KIA di wilayah kerja Puskesmas Sleman belum dimanfaatkan secara maksimal.

Berdasarkan hasil studi pendahuluan yang dilaksanakan di Puskesmas Tempel 1 didapatkan jumlah rata-rata kunjungan ibu hamil dari bulan Juli-September 2018 sebanyak 100 orang/bulan, kemudian setelah dilakukan wawancara kepada 5 ibu hamil yang melakukan ANC, semua ibu hamil trimester III membawa buku KIA dan membaca secara sepintas. Ibu yang mengetahu isi dan memanfaatkan buku KIA 1 orang dan 4 orang ibu hamil kurang mengetahui isi dan memanfaatkan buku KIA. Dari wawancara tersebut menunjukan pada ibu hamil trimester III banyak yang belum mengetahui isi dan memanfaatkan buku KIA dilihat dari banyaknya ibu hamil yang melakukan persiapan persalinan walaupun sudah memasuki usia kehamilan di trimester III. 


\section{Metode}

Penelitian ini penelitian ini adalah kuantitatif dengan desain penelitian deskriptif kuantitatif. Sampel dalam penelitian ini adalah semua ibu hamil yang melakukan pemeriksaan kehamilannya di Puskesmas Tempel, ibu hamil yang mempunyai buku KIA, ibu hamil yang bersedia menjadi responden yang memenuhi criteria inklusi dan eksklusi. Pengumpulan data menggunakan data primer berupa kuesioner. Analisis data dalam penelitian ini hanya menggunakan univariat yaitu menganalisa variabel yang ada secara deskriptif dengan menghitung distribusi dan presentasi dari setiap variabel (Notoajmodjo, 2010). Penelitian ini hanya mendeskripsikan pengetahuan responden tentang perilaku pemanfaatkan buku KIA selama masa kehamilan. Analisis data dilakukan dengan menghitung persentase.

\section{Hasil dan Pembahasan}

Berdasakan hasil penelitian didapatkan hasil sebagai berikut:

Tabel 1. Gambaran pemanfaatan buku KIA

\begin{tabular}{ccccccc}
\hline \multirow{2}{*}{ Karakteristik } & \multirow{2}{*}{ Jumlah (n) } & Persentase (\%) & Penggunaan buku KIA & \multicolumn{3}{c}{ Informasi buku KIA } \\
& & & $\mathrm{n}$ & $\%$ & $\mathrm{n}$ & $\%$ \\
\hline Umur & & & & & & \\
\hline$<20$ th atau $>35$ th & 12 & 20 & 12 & 20 & 12 & 20 \\
\hline 20-35 tahun & 48 & 80 & 48 & 80 & 48 & 80 \\
\hline Pendidikan & & & & & & \\
\hline Rendah & 18 & 30 & 18 & 30 & 18 & 30 \\
\hline Tinggi & 42 & 70 & 42 & 70 & 42 & 70 \\
\hline Pekerjaan & & & & & & \\
\hline Tidak bekerja & 25 & 41,6 & 25 & 41,6 & 25 & 41,6 \\
\hline Bekerja & 35 & 58,4 & 35 & 58,4 & 35 & 58,4 \\
\hline Paritas & & & & & & \\
\hline Multigravida & 28 & 46,6 & 28 & 46,6 & 28 & 46,6 \\
\hline primigravida & 32 & 53,4 & 32 & 53,4 & 32 & 53,4 \\
\hline
\end{tabular}

Berdasarkan tabel 1 didapatkan penggunaan buku KIA terbanyak pada kelompok umur 20-35 tahun sebesar 48 (80\%) responden dengan tingkat pendidikan tinggi sebanyak 2 (70\%) responden, paritas multigravida sebanyak 28 ( 46,6\%) dan pada ibu tidak bekerja sebesar 25 (41,6\%) responden. Sedangkan informasi buku KIA didapatkan informasi dengan baik pada responden umur 20-35 tahun sebanyak 48 (80\%) responden, dengan latar pendidikan tinggi sebesar 42 (70\%) responden, paritas 
multigravida sebesar 28 (46,6\%) responden dan ibu tidak bekerja sebesar 25 ( 58,4\%) responden. Penelitian ini bertujuan mengetahui gambaran pemanfaatan buku KIA oleh ibu hamil di Puskesmas Tempel 1. Gambaran pemanfaatan buku KIA oleh ibu hamil dalam penelitain ini terbagi dalam dua kategori pemanfaatan penggunaan buku KIA dan pemanfaatan informasi buku KIA mengenai persiapan persalinan. Hasil penelitian yang dilakukan selama 4 bulan dari bulan April sampai Agustus didapatkan semua responden (100\%) ibu hamil memiliki Sikap positif dalam pemanfaatan Buku KIA baik dilihat dari jawaban kuesioner penggunaan dan pemanfaatan informasi Buku KIA mengenai persiapan persalinan.

Hasil penelitian ini mendukung penelitian Sistiarani (2014) ibu yang mempunyai buku KIA mempunyai pengetahuan KIA dan perilaku yang lebih baik tentang KIA karena mempergunakan buku KIA dengan baik pula, dibandingkan kelompok kontrol pada ibu yang tidak mempunyai buku KIA. Hal ini disebabkan ibu yang selalu membawa buku KIA dalam pemeriksaan kehamilanya akan lebih percaya diri karena tahu kondisi kesehatannya. Buku KIA tidak hanya digunakan saat pemeriksaan kehamilan tetapi juga untuk pemantauan kesehatan anak yang dikandung sampai usia balita, sehingga ibu tersebut juga akan tahu perkembangan kesehatan anaknya. Buku KIA dalah buku catatan terpadu yang digunakan dalam keluarga dengan tujuan meningkatkan praktik keluarga dan masyarakat dalam pemeliharaan atau perawatan kesehatan ibu dan anak serta meningkatkan kualitas pelayanan KIA.

Penelitian yang dilakukan oleh Mori (2015) didapatkan bahwa ibu yang menggunakan buku KIA akan meningkatkan angka kunjungan pemeriksaan kehamilan dibandingkan dengan ibu yang tidak memanfaatkan buku KIA. Sedangkan pada ibu dengan komplikasi kehamilan, buku KIA lebih digunakan sebagai deteksi tanda bahaya kehamilanya. Penelitian Osaki et al dalam Mori (2015) di dapatkan ibu yang menggunakan buku KIA memanfaatkan layanan kesehatan dan persalinan ditolong oleh tenaga kesehatan.

Penelitian Nzioki et al (2015) yang dilakukan di Kenya bahwa ibu yang menggunakan buku KIA cendeung kan memanfaatkan layanan kesehatan yang ada dengan melakukan kunjungan ANC minimal 4 kali sesuai dengan ketetapan WHO. 
Gambaran pemanfaatan penggunaan buku KIA berdasarkan umur, pendidikan pekerjaan dan paritas berdasarkan penelitain ini didapatkan hasil yang baik. Berbeda dengan penelitian yang dilakukan Paramita dkk (2012) didapatkan sebesar 61,2\% ibu hamil di BPM Ny.E dikategorikan kurang dalam memanfaatatkan buku KIA untuk memperoleh informasi tentang tanda-tanda bahaya kehamilan. ibu hamil kurang memanfaatkan buku KIA selama kehamilan hal ini tidak sesuai anjuran (Kemenkes, 2015) bahwa penggunaan buku KIA oleh ibu hamil yaitu berperan aktif membaca dan mengerti isi buku KIA dengan benar, jika ada yang tidak dipahami bertanya pada kader dan atau petugas kesehatan.

Berdasarkan pendidikan didapatkan bahwa sebagian besar responden berpendidikan tinggi sebanyak 42 responden. Diketahui bahwa responden dengan pendidikan tinggi memanfaatkan buku KIA dengan baik. Hal ini sesuai dengan Notoatmodjo (2010) mengatakan faktor yang mempengaruhi perilaku dalam pemanfaatan buku KIA adalah faktor predisposisi yang terwujud dalam pengetahuan, sikap, kepercayaan, nilai-nilai, tingkat pendidikan. Tingkat pendidikan dan pengetahuan sangat berpengaruh terhadap perubahan sikap dan perilaku. Tingkat pendidikan yang tinggi akan memudahkan seseorang atau masyarakat untuk menyerap informasi dan mengaplikasikan dalam kehidupan sehari-hari, khususnya dalam hal kesehatan. Hasil penelitian dilihat dari pendidikan dengan pemanfaatan buku KIA oleh ibu hamil menunjukan kategori paling banyak berada pada jenjang pendidikan tinggi sebanyak $80 \%$. Notoatmodjo (2010) pendidikan dapat memengaruhi seseorang termasuk juga pola hidup terutama dalam memotivasi untuk berperan serta dalam pembangunan kesehatan. Peran serta ibu hamil dalam bidang kesehatan diwujudkan dalam aktifnya memanfaatkan dan menggunakan buku KIA sebagai panduan dalam pemberian informasi/layanan KIA. Pendidikan yang rendah akan memengaruhi pengetahuan yang dimiliki ibu hamil. Semakin tinggi pendidikan yang dimiliki oleh ibu hamil maka semakin tinggi penegetahuan dan kesadaran akan tanggung jawab terhadap kesehatannya. Berdasarkan umur responden berada pada usia reproduksi sehat rentang usia 20-35 tahun sebanyak 48 responden (80\%) positif 
menggunakan buku KIA . Hasil penelitian ini sesuai dengan penelitian yang dilakukan Sartika dkk (2014) yang menyatakan usia berpengaruh terhadap pemenfaatan buku KIA. Green (2005) menyatakan bahwa semakin cukup usia, tingkat kematangan seseorang akan lebih baik, ketika kematangan usia seseorang cukup tinggi maka pola pikir akan menjadi lebih dewasa.

Hasil penelitian dilihat dari gravida dengan pemanfaatan buku KIA oleh ibu hamil semua menunjukan kategori positif baik primi maupun multi gravida. Sebagian besar resonden adalah multigravida. Hal ini tidak sesuai dengan teori yang dikemukakan oleh Notoatmodjo (2010), ibu yang pertama hamil akan memiliki motivasi tinggi untuk memeriksakan kehamilan. Sedangkan ibu yang sudah hamil yang kedua kali atau lebih cenderung lebih jarang dalam melakukan pemeriksaan kehamilan karena beranggapan telah memiliki pengalaman dalam menjaga kahamilannya. Hasil

penelitian dilihat dari pekerjaan dengan pemanfaatan buku KIA oleh ibu hamil menunjukan bahwa kategori paling banyak terdapat pada ibu hamil yang bekerja sebanyak 35 responden (58,3\%) dan 25 responden ibu hamil tidak bekerja dengan hasil semua positif dalam pemanfaatan buku KIA. Berdasarkan hasil penelitian tersebut didapatkan bahwa ibu yang tidak bekerja lebih banyak waktu untuk memerhatikan kehamilannya dan mendapat informasi mengenai kesehatan ibu dan janin melalui tenaga kesehatan. Hal ini berlawanan dengan teori yang dikemukakan Green (2005) bahwa ibu yang bekerja memiliki kesibukan yang banyak sehingga tidak sempat untuk memeriksakan kehamilannya. Hal ini bisa terjadi karena ibu hamil banyak mendapat informasi dari tempat pekerjaannya untuk tetap melakukan pemeriksaan kehamilan. Penelitian Nzioki ( 2015) didapatkan bahwa perilaku kesehatan ibu hami di Eutopia dipengaruhi salah satunya oleh pekerjaan.

Secara kuantitas bahwa pemanfaatan penggunaan buku KIA dalam penelitian ini semua responden mempunyai nilai positif, tetapi dalam hal kualitas berdasarkan hasil wawancara dengan beberapa responden ibu hamil masih beranggapan buku KIA hanya wajib dibaca oleh tenaga kesehatan dan ibu hamil seharusnya buku KIA boleh dibaca oleh suami dan keluarga untuk mengetahui kesehatan ibu dan perkembangan janin. Hal tersebut sesuai dengan Sastiarani, dkk 
(2014) menunjukan bahwa ada hubungan pengetahuan tentang buku KIA dengan kualitas penggunaan buku KIA. Pengetahuan tentang buku KIA akan meningkatkan kepatuhan ibu dalam penggunaan buku KIA sehingga dapat meningkatkan derajat kesejahteraan ibu dan anak.

Hasil penelitian Pemanfaatan buku KIA oleh ibu hamil dilihat dari pemanfaatan informasi buku KIA didapatkan hasil 100\% dalam kategori baik. Hasil penelitian menggambarkan responden mengetahui informasi kesehatan dari isi buku KIA. Hal tersebut sesuai dengan penelitian yang dilakukan oleh Nzioki (2015) bahwa ibu yang memanfaatkan buku KIA cenderung mencari informasi terkait kesehatan ibu dan bayi seperti dalam hal akses pelayanan ANC, perawatan masa nifas, imunisasi bayi dan penggunaan KB setelah 6 bulan persalinan. Pemanfaatan informasi tersebut berupa informasi mengenai persiapan persalinan yang akan dilakukan oleh ibu hamil. Disini baik dari kesiapan ibu, keluarga dan bidannya dalam mempersiapakan seorang ibu hamil yang akan melakukan persalinan. Dari informasi yang didapatkan penjelasan mengenai persiapan persalinan dijelaskan oleh bidan yang ada di Puskesmas Tempel 1 tersebut. Bidan dalam menjelaskan menggunakan panduan dari buku KIA yang sudah dimiliki oleh masing-masing ibu hamil. Baik berupa persiapan secara fisik dan psikis ikut dipersiapkan.

Responden memiliki beberapa karakteristik dan setiap responden memiliki latar belakang yang menentukan tingkat perilakunya, hal ini disebabkan karena adanya salah satu faktor yang mendominasi tingkat perilakunya. Green (2005) menjelaskan bahwa faktor pembentuk perilaku seseorang adalah faktor predisposisi (presdisposing faktors) yang terwujud dalam pengetahuan, sikap, kepercayaan, keyakinan, nilai-nilai, tingkat pendidikan, tingkat sosial yang terdapat dalam individu maupun masyarakat. Penelitian yang dilakukan oleh Kusumayati dan Nakamura (2007) dilakukan penelitian di Sumatra Barat menggunakan teori Green bahwa yang menjadi faktor predisposing adalah umur, pendidikan, pekerjaan dan pendapatan. Sedangkan faktor status sosial ekonomi, dan ukuran keluarga dan faktor Reinforcing adalah dukungan dari tenaga kesehatan dan dukungan dari bidan yang ada di wilayah tersebut. 
Tingkat pendidikan dan pengetahuan sangat berpengaruh terhadap perubahan sikap dan perilaku. Semakin tinggi tingkat pendidikan, sikap dan kepercayaan ibu hamil maka semakin mudah menerima informasi dan semakin tinggi pula kesadaran ibu dalam berperilaku menggunakan dan memanfaatkan buku KIA. Pada ibu hamil dengan pendidikan tinggi diharapkan banyak mengetahui dan memperoleh informasi yang berkaitan dengan kesehatan. Hasil dari penelitian di Puskesmas Sleman bahwa responden mayoritas berlatar belakang pendidikan tinggi, meskipun demikian ibu hamil dalam memperoleh sumber infomasi dan pengetahuan baru tentang pemanfaatan buku KIA tersedia beragam alternatif sumber informasi yang bisa diperoleh ibu dalam memenuhi kebutuhan informasi kesehatan.

Upaya peningkatan informasi yang dapat dilakukan ada dengan penggunaan buku KIA oleh ibu. Informasi terkait dengan KIA sudah semakin mudah di akses oleh ibu dengan melalui interaksi ibu dengan tenaga kesehatan, media informasi kesehatan lainya sehingga meningkatkan pemahaman ibu tentang informasi kesehatan ibu dan anak. Berdasarkan hasil penelitian didapatkan bahwa sebagin besar responden berada dalam rentang umur reproduktif. Rentang umur reproduktif adalah masa berkembangnya daya tangkap dan pola pikir sehingga akan mempengaruhi pengetahuan dan informasi yang diperoleh semakin baik. Penelitian (2015) didapatkan buku KIA mempunyai efektifitas dalam meningkatkan informasi pada ibu, sehingga ibu bersedia melakukan kunjungan ANC.

Berdasarkan pendidikan diketahui bahwa pemanfaatan informasi digunakan dengan baik. Hal tersebut sesuai dengan penelitian yang dilakukan oleh Nzioki (2015) bahwa faktor-faktor penentu pemanfaatan informasi kesehatan pada ibu dengan pendidikan menegah dan tinggi. $\mathrm{Hal}$ tersebut karena pencarian informasi yang diperoleh melalui pendidikannya dan oleh karena itu mereka cenderung mencari perawatan kesehatan yang lebih baik dan informatif. Penelitian yang dilakukan oleh Kusumayanti (2007) bahwa ibu yang menggunakan buku KIA akan meningkatkan pengetahuan ibu, sehingga ibu akan melakukan pemeriksaan ANC minimal dan melakukan imunisasi TT 2 kali selama 
kehamilan dan pentingnya imunisasi TT selama kehamilan.

\section{Kesimpulan}

Pemanfaatan buku KIA oleh ibu hamil trimester III di Puskesmas Tempel 1 memiliki kategori positif artinya buku KIA ini dimanfaatkan oleh ibu hamil dalam melakukan persiapan persalinan.

\section{Daftar Pustaka}

Arikunto, 2013. Prosedur Penelitian Suatu Pendekatan Praktek. Jakarta: Rineka Cipta.

Azwar, Saifudin. 2011. Penyusunan Skala Psikologi. Yogyakarta: Pustaka Pelajar.

Budiman, dan Riyanto. (2013). Kapita Saleka Kuesioner : Pengetahuan dan Sikap Dalam Penelitian Kesehatan. Jakarta: Salemba Medika.

Buku Kesehatan ibu dan Anak Departemen Kesehatan Republik Indonesia. 2015. Bakti Husada Kementrian Kesehatan Republik Indonesia.

Colti, Sistiarini., Gamelia, Elviera., Sari, Dyah. (2014). Fungsi Pemanfaatan Buku KIA terhadap Pengetahuan Kesehatan Ibu dan Anak pada Ibu. Jurnal Kesmas National Public Health Journal Vo. 8 No. 8.

Dinkes Sleman, 2015. Profil Kesehatan Kabupaten Sleman Tahun 2014. Yogyakarta: Dinkes Sleman.

Ernoviana, M, H. 2006. Pemanfaatan Buku Kesehatan Ibu dan Anak di Dinas Kesehatan Kota Sawahlunto. Yogyakarata. Unuversitas Gadjah Mada.
Farodis, Zian. 2012. Panduan Lengkap Menejemen Kebidanan. Yogyakarta: D- Medika.

Green, Lowrence., Kreuter, W. 2005. Helath Promotion Planning: An Educational and Ecological Approach. 4th Edition New York: McGraw Hill.

Hani, U, dkk. 2011.Asuhan Kebidanan Pada Kehamilan Fisilogis. Jakarta: Salemba Medika.

Hidayat, Aziz Alimul (2007). Metode Penelitian Kebidanan Teknis Analisis Data. Surabaya: Salemba.

Kamus Umum Bahasa Indonesia. 2015. Tersedia dalam http://www.definisipengertian.com/2 015/07/definisi-pengertianpemanfaatan.html diakses pada 15 Juni 2016.

Kemenkes R.I. 2015, Petunjuk Teknis Penggnaan Buku Kesehatan Ibu dan Anak (KIA). Jakarta: Kemenkes RI.

Kemenkes RI. 2013. Riset Kesehatan Dasar 2013.Jakarta: Badan Penelitian Pengembangan Kesehatan RI.

Kemenkes RI. 2014. Profil Kesehatan Indonesia. Jakarta: Kemenkes RI.

Kemenkes RI. 2015. Profil Kesehatan Indonesia. Jakarta: Kemenkes RI.

Kusumayanti, Agustin., Nakamura, Yasuhide. 2005. Increased Utilization of Maternal Health Service by Mothers Using the Maternal and Child Helah Handbook in Indonesia. Journal of International Helat Vol. 22 No. 3

Lestari dan Titik. (2015). Kumpulan Teori Untuk Kajian Pustaka Penelitian Kesehatan. Yogyakarta: Mulia Medika. 
Mahmudah, W 2016, Pemanfaatan Buku KIA oleh Ibu Hamil di Puskesmas Kalasan Yogyakarta, Karya Tulis IImiah

Marmi, 2011. Asuhan Kebidanan Pada Masa Antenatal. Yogyakarta: Pustaka Pelajar.

Mori, Rintaro., Yonemato, Naohiri., Noma, Hisashi et al. 2015. The Maternal and Child Helat (MCH) Handbook in Mongolia: A ClusterRandomized, Controlled Trial. Journal.pone DOI: 10.1371.

Mufdlilah. 2009. ANC FOKUS. Yogyakarta: Nuha Medika.

Nirwana, 2011. Kapita Selekta Kehamilan. Yogyakarta: Nuha Medika.

Notoatmojdo, 2012. Metodologi Penelitian Kesehatan. Jakarta: PT Rineka Cipta.

Notoatmojdo, 2014. IImu Perilaku Kesehatan. Jakarata: PT Rineka Cipta.

Nursalam. 2008. Konsep dan Penerapan Metodologi Penelitian Ilmu Kepeawatan. Jakarta : Salemba Medika.

Nzioki, Japhet., Onyango, Rosebella., Ombaka, James. 2015. Socio demographic Factors
Influencing Maternal and Child Mental Helat Service Utilization in Mwingi: A rural SemiArid District in Kenya. American Journal of Public Healt Reseach Vol. 3 No. 1, 21-30

Paramita dkk. Hubungan antara Pemanfaatan Buku KIA dengan Tingkat Pengetahuan dan Sikap Ibu Hamil tentang Tanda-tanda Bahaya Kehamilan di BPM Ny. E Kecamatan Ambarawa Periode Januari-Maret 2012; 3(1) :40-47.

Riwidikdo, H. (2009). Stastik Kesehatan. Yogyakarta: mitra Cendekia Press.

Sartika., (2014). Hubungan Penegetahuan dan Sikap Ibu Hanil Tentang Antenatal Care Dengan penggunaan Buku KIA di Wilayah Kerja Puskesmas Ranotana Weru Kecamatan Wanea Manad.

Sugiyono. 2015. Statistika Untuk Penelitian. Bandung: Alfabeta.

Wawan, A dan Dewi, M, 2010. Teori Pengukuran Pengetahuan, Sikap, dan Perilaku Manusia, Yogyakarta: Nuru Medika. 